\title{
Outcome of early intervention in infants at risk of developmental delay: a pilot study
}

\author{
H Perera ${ }^{1}$, D Weerasinghe ${ }^{2}$, Y I P de Silva ${ }^{2}$, P Weliwatta ${ }^{2}$, H N K Dharmalatha ${ }^{2}$ \\ Sri Lanka Journal of Child Health, 2007; 36: 48-52
}

(Key words: early intervention, infant development, developmental disorders, home based programme)

\begin{abstract}
Objectives To assess the outcome of a home based psychosocial intervention programme on facilitating development in infants at risk of developmental delay.
\end{abstract}

Method Three groups of infants were involved. Group I comprised infants who suffered from adverse pregnancy and perinatal events and received psychosocial intervention. Group II comprised infants born during the same period with no similar risks and no intervention. Group III comprised infants who had adverse pregnancy and perinatal experiences but did not receive any intervention. Group 1 mothers were trained to carry out structured activities at home with the infant, adapted from the Portage Model. Outcome was measured at 12 months of age. The scores in 12 different skills in 5 developmental domains in the three sample groups were compared at the end of 12 months.

Results Mean developmental scores in Groups (Gps) I $(n=36)$, II $(n=32)$ and III $(n=9)$ were $10.00,10.75$ and 3.11 respectively. Independent sample $t$ test showed no statistically significant difference in developmental scores at 12 months between Gps I and II $(p=0.242$, mean difference $0.750,95 \% \mathrm{CI}$ 2.019 to 0.519$)$. Difference in developmental scores between Gps I \& III was highly significant ( $p=0.000$, mean difference 6.889 , 95\% CI 4.588 to 9.189 ).

Conclusion Early intervention is effective and feasible in preventing developmental delay.

${ }^{1}$ Professor of Psychological Medicine, Faculty of Medicine, Colombo. ${ }^{2}$ Public Health Nursing Sister, MOH Division, Panadura

(Received on 23 June 2006. Accepted on 20 July 2006).

\section{Introduction}

Prevalence of developmental disorders in children in non-industrialised countries is $12-29 \%{ }^{1}$. Prevalence for Sri Lanka probably falls within this range, as indicated by population based studies. For example, a study, which assessed developmental readiness for school entry at 5 years of age, showed delayed cognitive development in $17.8 \%$, leading them to being less ready to commence formal education ${ }^{2}$. Further, a study on mental health problems of urban preschool children identified delayed language development alone in $10 \%{ }^{3}$.

Many children with clinically identifiable developmental problems present late for medical help due to low rate of early recognition. For example, $34.5 \%$ of referrals to a specialist child mental health outpatient service were for developmental delay and learning disabilities, but the majority of referrals were over 5 years of age at the time of seeking help ${ }^{4}$. Though $49.9 \%$ of these children had delayed early motor and language milestones and $24.3 \%$ had suffered adverse birth and perinatal events, these negative prognostic indicators were not acted upon with earlier developmental interventions.

In industrialized countries, community based intervention programmes for developmentally delayed children have been available for over three decades. These programmes are based on a range of biological, social-ecological and psychodynamic models. Irrespective of the cause of the developmental disorder, these intervention programmes are designed to improve skills, educational attainment and quality of life and prevent behavioural problems. A few such programmes are, the "Head Start" in the United States (US), "Sure Start" in the United Kingdom (UK) and "Portage Early Education Programme" in US and UK. Most programmes require high resource utilization and mainly target the infant and preschool age groups. 
Rationale for intervention commencing in infancy as opposed to preschool years is supported by recent advances in knowledge on neuro-biological processes associated with development. It has been shown that development of cognitive skills is related to significant structural changes in brain during perinatal period and first few months after birth. These changes include increase in brain weight and neuronal density, rapid dendritic arborisation and synaptogenesis and functional specialization ${ }^{5,6}$. Hence, the outcome of developmental intervention is optimal if applied in infancy as synaptic connections are unlikely to establish later. In addition, as the shaping of brain structures and strengthening of connections takes place, there is weakening and elimination of unused connections ${ }^{7}$. Therefore, psychosocial stimulation should be provided in infancy to obtain the best benefit. This approach is especially relevant for cognitive and language development, even though clinical evidence of developmental delay in these skills may not be apparent at this early stage. Considering the above mentioned evidence, this study examines the effectiveness and feasibility of using a psychosocial intervention programme in early infancy in those who are identified at birth with risk factors for later developmental delay.

\section{Objectives}

- To assess outcome of a psychosocial intervention programme on infants who were detected at birth to have a potential for developmental delay from exposure to adverse pregnancy and perinatal risk factors.

- To compare the above outcome at 12 months of age with infants without such risks and those with risks who did not receive any intervention.

\section{Design, setting and method}

This was a prospective study, where the infants were followed up until 12 months of age. The study area was the Medical Officer of Health (MOH) Division, Panadura. Three groups of infants participated in study, all from the same study area. Group I was the experimental group comprising infants identified at birth as having suffered single or multiple adverse events during pregnancy, at birth or in the first 24 hours. This sample was collected from infants born over a period of 2 months at the local maternity hospital. Group II was a randomly selected control group comprising infants born during the same period at the same maternity hospital, but with no reported adverse perinatal experiences. These infants were not offered any intervention. Group III was also a control group comprising infants (older by 1-3 months to Groups I and II infants) who had adverse perinatal events but did not receive any intervention. This was a convenient sample.

Social and health related data about parents were collected using a structured format. Pregnancy related data were gathered by interviewing mother and from available clinical records. Information on the perinatal period and occurrence of any adverse events were obtained by interviewing healthcare personnel of the maternity unit and clinical records.

Selected structured activities from the "Infant Stimulation" section of Portage Early Education Programme ${ }^{8,9}$, suitably modified for local culture, was used in the developmental intervention. Portage programme offers activities to assist in development of motor, cognitive, language, self-help and social skills. Mothers of Group I infants were trained to carry out these selected structured activities at home with their infants. These activities, which were at different levels of complexity, were initiated when infant was 6 weeks old and continued through to 12 months. In addition to training, each mother was provided with a printed handout describing the activities. Certain play tools, necessary for the activities, were made at home by mothers with readily available low cost material. The mother and infant pairs were seen individually and in groups for monitoring and support. Infants in all 3 study groups also received all other services offered to them at primary healthcare clinics. The sampling, data collection, training of mothers and monitoring, and all assessments were carried out exclusively by the 4 authors.

Twelve items of skills adapted from the Portage development checklist (appropriate to 12 months of age) in 5 developmental domains (motor, cognitive, language/communication, socializing and self-help) were measured at 12 months of age. Presence or absence of each skill was noted after testing and accordingly, was given a score of 1 or 0 . Assessments to measure outcome was carried out exclusively by the 4 authors. Ethical Clearance was obtained from the Ethical Review Committee, Faculty of Medicine, Colombo

\section{Results}

The comparative frequency distribution of data of infant and mother related variables in the sample groups I, II and III is shown in table 1. The comparative frequency distribution of adverse events 
in pregnancy for each sample group is shown in table 2 . The comparative frequency distribution of adverse events during the perinatal period in each sample group is shown in table 3 .

Table 1

Comparative frequency distribution of data of infant and mother related variables in sample groups I, II and III

Variables

Sex ratio $\mathrm{M} / \mathrm{F}$ of infants

Mother's age 18-30 yrs. 31-40 yrs. $>40$ yrs.

Family type - extended nuclear

Mother's educational level

Advanced level

Ordinary level

Primary school

Not attended

Mother's employment

House wife

State sector employee

Private sector employee

Range of developmental scores in infants at 12 months of age (maximum score 12)

$$
\begin{aligned}
& -0 \text { to } 4 \\
& -5 \text { to } 8 \\
& -9 \text { to } 10 \\
& -11 \text { to } 12
\end{aligned}
$$

Mean developmental score in the infants

$\begin{array}{ccc}\text { Group I (n=36) } & \text { Group II }(\mathbf{n}=\mathbf{3 2}) & \text { Group III }(\mathbf{n}=\mathbf{9}) \\ 20 / 16(1: 0.8) & 15 / 17(1: 1.1) & 2 / 7(1: 3.5) \\ 25(69.4 \%) & 22(68.8 \%) & 05(55.6 \%) \\ 11(30.6 \%) & 09(28.1 \%) & 04(44.4 \%) \\ 0 & 01(02.8 \%) & 0(0 \%) \\ 18(50 \%) & 11(34.4 \%) & 04(44.4 \%) \\ 18(50 \%) & 21(65.6 \%) & 05(55.6 \%)\end{array}$

$$
\begin{gathered}
11(30.6 \%) \\
17(47.2 \%) \\
08(22.2 \%) \\
0(0 \%)
\end{gathered}
$$

$$
11(34.4 \%)
$$$$
01(11.1 \%)
$$$$
06(66.7 \%)
$$$$
02(22.2 \%)
$$$$
0(0 \%)
$$

$$
\begin{aligned}
& 28(77.8 \%) \\
& 06(16.7 \%) \\
& 02(05.6 \%)
\end{aligned}
$$$$
27(84.4 \%)
$$$$
02(06.3 \%)
$$$$
03(09.4 \%)
$$$$
\text { 4-12 }
$$

$09(100 \%)$

$0(0 \%)$

$0(0 \%)$

$$
\text { 0-12 }
$$

$$
\begin{gathered}
02(05.6 \%) \\
0(0 \%) \\
14(38.9 \%) \\
20(55.6 \%)
\end{gathered}
$$

$$
\begin{aligned}
& 01(03.1 \%) \\
& 03(09.4 \%) \\
& 04(12.5 \%) \\
& 24(75.0 \%)
\end{aligned}
$$

0-10

10.00
$07(77.8 \%)$

$$
0(0 \%)
$$

$01(11.1 \%)$

$01(11.1 \%)$

Table 2

Comparative frequency distribution of adverse events in pregnancy for each sample group

$\begin{array}{lccc}\text { Adverse Event } & \text { Group I n (\%) } & \text { Group II n (\%) } & \text { Group III n (\%) } \\ \text { Hypertension } & 15(41.3) & 02(06.3) & 02(22.2) \\ \text { Diabetes } & 03(08.3) & 0 & 0 \\ \text { Anaemia } & 02(05.4) & 0 & 01(11.1) \\ \text { APH } & 01(02.7) & 0 & 0 \\ \text { Heart disease } & 01(02.7) & 0 & 0 \\ \text { Other } & 06(16.6) & 0 & 01(11.1)\end{array}$


Table 3

Comparative frequency distribution of adverse events during perinatal period

in each sample group

$\begin{array}{lccc}\text { Event } & \text { Group I n (\%) } & \text { Group II } & \text { Group III n (\%) } \\ \text { Birth before 37 weeks } & 10(27.7) & 0 & 03(33.3) \\ \text { Birth weight }<2.5 \mathrm{~kg} & 25(69.4) & 0 & 03(33.3) \\ \text { Apgar score }<7 & 05(13.8) & 0 & 04(44.4) \\ \text { Septicaemia } & 04(11.1) & 0 & 0 \\ \text { Neonatal Fits } & 01(02.7) & 0 & 01(11.1) \\ \text { Hypoglycaemia } & 02(05.4) & 0 & 0 \\ \text { Delayed crying after birth } & 07(19.4) & 0 & 0 \\ \text { Delayed 2nd stage labour } & 04(11.1) & 0 & 0 \\ \text { Meconium aspiration } & 06(16.6) & 0 & 0 \\ \text { Other } & 01(02.7) & 0 & 0\end{array}$

There was no statistically significant difference between the age, educational level and employment status of mothers, and the family type between the infants in Group I and group II $(p>0.05)$. In all, the 36 infants in Group I had experienced 28 pregnancyrelated and 67 perinatal adverse events, which on average showed 2.6 risk events per infant. In all, the 9 infants in Group III had 4 pregnancy-related and 11 perinatal adverse events, which on average showed 1.6 risk events per infant. In contrast, Group II had 0.06 risk events per infant. Independent $t$ Test showed that there was no significant difference in developmental scores between Group I and Group II ( $p=0.242$, mean difference $0.750,95 \%$ CI 2.019 to $0.519)$. There was a highly significant difference in developmental scores between Group I and Group III ( $p=0.000$, mean difference $6.889,95 \%$ CI 4.588 to 9.189). All infants in Group I completed the 12 month programme with no interruptions.

\section{Discussion}

In this study, developmental intervention was started in early infancy, before any clinical signs of developmental delay were evident. Presence of risk factors with known potential to cause developmental disabilities was considered enough justification for intervention. Other similar programmes have considered infants not only with perinatal risk factors but even non-affected siblings of developmentally disordered children and those with a history of neglect and abuse ${ }^{10}$. Furthermore, our results are supported by other community based studies from developing countries on infants and very young children with developmental risks resulting from varying aetiologies $11,12,13,14$. These studies too have shown good outcomes with early psychosocial intervention, when compared to no intervention or standard medical care only.

One can argue that some infants in Group I may have developed normally, despite the identified risks. While appreciating this possibility, it is also apparent that none of the infants in Group III reached normal developmental scores at 12 months of age (table 1). At the same time, the outcome of infants in the intervention group was similar to infants who had no identified risks. However, the raw developmental scores (table 1) show that despite early intervention, a comparatively higher proportion of infants in Group 1 reached middle range developmental scores and a lower proportion reached higher developmental scores at one year of age, when compared to Group II infants. These scores are sufficient indication of the risk status of Group I infants. Hence, if intervention was not offered, the likelihood of these infants suffering from a developmental delay at one year could be presumed as high, as in Group III. Further, available knowledge on neurobiological processes related to infant development ${ }^{5,6,7}$ does not justify a "wait and see" approach. Furthermore, the low predictive validity considered inherent in the normal ranges of developmental milestones, traditionally used in clinical practice ${ }^{15,16}$, and the fact that unstructured assessments lead to missing as many as $70 \%$ of children with developmental problems ${ }^{16,17}$, is sufficient grounds to reject a "wait and see" approach. Of particular relevance to Sri Lanka is the fact that the Child Health Development Record (CHDR), widely used in the community, is an unstructured screening tool for development, as it does not provide practical guidelines to the user to enable reliable assessments. Other variables, which may have contributed to development of the infants, such as maternal age, educational level and employment status of mothers, did not show any significant difference between Groups I and II. 
An additional positive contribution for infant development in our programme was the support provided to parents and their active involvement in the interventions. Benefits of such methods have been recognized in similar studies, where progress in development as well as improved parenting skills was observed $^{10,18,19}$. Furthermore, we used items from the Portage Model that were suitably modified to meet the cultural needs and financial affordability of families. Other developing countries such as India, Bangladesh and Jamaica have successfully used the Portage Model with modifications on similar lines ${ }^{20}$.

There are several shortcomings in the study. Firstly, the small sample size, especially in Group III. Secondly, study population was restricted to a single semi-urban area. Thirdly, if the outcome measures were conducted blind, it would have added more value to the study. Finally, our programme was mostly child focused, but child and family focused intervention programmes are being encouraged more for their additional benefits ${ }^{10}$.

\section{Conclusions}

Home based psychosocial intervention in the first 12 months for infants at risk of developmental delay is effective and feasible. Further study is needed on a larger population of such infants and their families, with follow up for a longer period to validate the effectiveness of the programme.

\section{References}

1. The World Health Report 2001. Mental Health: new understanding, new hope. In Chapter 2: Burden of mental and behavioural disorders. World Health Organization, Geneva. 19-44.

2. Perera H. Readiness for school entry: a community survey. Public Health 2005; 119: 283-9.

3. Perera H, Gunatunge C. Mental health of preschool children. Sri Lanka Journal of Child Health 2004; 33:39-42.

4. Perera H, Perera R. User satisfaction with child psychiatry outpatient care: implications for practice. Ceylon Medical Journal 1998; 45: 18590.
5. Werry JS, Zametkin A, Ernst M. Brain and behaviour In: Child and Adolescent Psychiatry, a comprehensive textbook. Ed: Melvin Lewis. Lippincott, Williams and Wilkins, Philadelphia 2002, 120-132.

6. Anastasiow NJ. Implications of the neurobiological model for early intervention. In: Handbook of Early Childhood Intervention, Ed: Samual J Meisles \& Jack P Shonkoff. Cambridge University Press 1998, 196-216.

7. National Research Council and Institute of Medicine 2000. Available from: www.ehsnrc.org/PDF files/TA8.pdf Accessed in February 2006.

8. Cameron RJ, White M. Portage Early Education Programme. Available from:

www.portageproject.org Accessed in February 2006.

9. Cameron RJ. Early intervention for young children with developmental delay: the Portage approach. Child: Care, Health and Development 1997; 23:11-27.

10. Gine C, Vilaseca R, Gracia M, Garcia-Die MT. Early intervention in Spain - some directions for future development. Infants and Young Children 2004; 17: 247-57.

11. Gottlieb G, Blair C. How early experience matters in intellectual development in the case of poverty. Prevention Science 2004; 5: 245-52.

12. Parker S, Greer S, Zuckerman B. Double jeopardy: the impact of poverty on early child development, a review. Pediatric Clinics of North America 1988; 35: 1227-40.

13. Powell C, Baker-Henningham $\mathrm{H}$, Walker $\mathrm{S}$, Gernay J, Grantham McGregor S. Feasibility of integrating into primary care for undernourished Jamaican children: cluster randomized controlled study. British Medical Journal 2004; 329: 89.

14. Eickmann SH, Lima AC, Guerra MQ, Lima MC, Lira PI, Huttly SR, Ashworth A. Improved cognitive and motor development in a community-based intervention of psychosocial stimulation in Northeast Brazil. Developmental Medicine and Child Neurology 2003; 79: 28690. 
15. Earls M. Developmental and behavioural screening: a quality initiative in primary care practice. www.medscape.com CME conference. Accessed February 2006.

16. Romanczyk RG, Gillis JM, Moyes-Grosser DM, Holland JP. Clinical clues, developmental milestones, early identification / assessment of children with disabilities: practical applications and conceptual considerations. Infants and Young Children 2005; 18: 212.

17. Dawkins P. Child development, the science and practice of catching problems early. www.medscape.com CME conference. Accessed February 2006.
18. Regalado M, Halfon N. Primary care services promoting optimal child development from birth to age 3 years: review of the literature. Archives of Pediatric and Adolescent Medicine 2001; 155: 1311-22.

19. Dudley M, Gyler L, Blinkhorn S, Barnett B. Psychosocial interventions for very low birthweight infants: their scope and efficacy. Australia and New Zealand Journal of Psychiatry 1993; 27: 74-83.

20. Sturmey P, Thorburn MJ, Brown JM, Reed J, Kaur J, King G. Portage guide to early intervention: cross-cultural aspects and intracultural variability. Child: Care, Health and Development 1992; 18: 377-94. 
